\title{
Cumhuriyet döneminde bir taşra gazetesi: “Bozok"
}

\section{Funda ÇAPAN ÖZDEMİR}

\author{
APA: Çapan Özdemir, F. (2019). Cumhuriyet döneminde bir taşra gazetesi: “Bozok”. RumeliDE Dil \\ ve Edebiyat Araştırmaları Dergisi, (14), 353-360. DOI: 10.2900o/rumelide.541034
}

\section{Öz}

Yozgat basın tarihi, birbirindBaben farklı özelliklere sahip gazeteler ve gazetelerde çıkan haberlerin yanı sıra güncel, sosyal, siyasi, iktisadî ve kültürel konular hakkında kaleme alınan yazılar ve yazarlar bağlamında dikkate değer bir çeşitliliğe sahiptir. Yozgatlı yazar Abbas Sayar'ın sahibi olduğu “Bozok”, baskı, mizanpaj, sayfa adedi ve muhteva bakımından dönemine göre üstün özelliklere sahip ve Yozgat'ın meselelerini dikkate değer bir sunuş tarzıyla gündeme getiren mühim bir gazetedir. 1950'li yılların Yozgat'ında oldukça etkin olan bu gazetede çıkan yazılar, halkın değer yargılarını değiştirerek halk için bir "cesaret kapısı" haline gelir. Halkı okumaya teşvik eden, halkın siyasi, sosyal ve kültürel anlamda bilgi seviyesini yükselten mühim bir hizmettir. Yozgat sevdasıyla gazetecilik aşkını "Bozok" gazetesinde buluşturan Abbas Sayar, gazeteciliğin maddî ve manevî tüm zorluklarına katlanır. “Bozok” gazetesinin yazarları, Yozgat'ın menfaatleri doğrultusunda hareket etmeyi temel bir yayın politikası olarak benimserler. Türkiye genelinde Yozgat'ın siyasi, sosyal, kültürel ve ekonomik sorunlarını gayet ciddi bir biçimde ele alarak gündeme taşırlar. Bu bağlamda "Bozok", bölgesel gazeteciliğin sınırlarını zorlayan, memleket meselelerine duyarlı, gündem oluşturan ve güvenilir bir gazetedir. Çalışmamızda, Yozgat basın tarihinin fikrî planda en temsilî örneği olan "Bozok" gazetesinin 1953-1954 tarihleri arasında çıkan toplam 230 nüshasını, gazetenin sahibi olan Abbas Sayar'ın gazetecilik tecrübelerinden yola çıkarak, tematik bir araştırma konusu yaptık. İncelememiz, 1950'li yılların Yozgat'nna ait siyasi, sosyal ve kültürel meselelerin gazete sütunlarında nasıl, ne şekilde ve niçin ele alındığı gibi soruları da cevaplar niteliktedir. Türk edebiyatında daha çok roman ve şiir gibi türlerde kaleme aldığı eserleriyle tanınan Abbas Sayar'ın bir gazeteci olarak bilinmeyen yönlerini de aydınlatmaya çalıştık.

Anahtar kelimeler: Cumhuriyet dönemi, taşra gazetesi, Bozok.

\section{A provincial newspaper in the republican period: "Bozok"}

\begin{abstract}
The history of the Yozgat press has a considerable variety in the context of articles in contemporary, social, political, economic and cultural issues and in the context of news in different newspapers and newspapers. "Bozok", the author of Abbas Sayar in Yozgat, raises issues related to Yozgat's remarkable presentation style and an important newspaper with outstanding features such as print, page layout, page count and content. The articles published in this newspaper which was very influential in the Yozgat of the 1950s changed public values and became a gate of courage for the public. It is an important service that encourages the public to read in political, social and cultural terms and to increase the level of knowledge of the people. Abbas Sayar brings his love of journalism to the newspaper "Bozok" with the love of Yozgat. The writers of the Bozok newspaper adopted the
\end{abstract}

1 Dr. Öğr. Üyesi, Yozgat Bozok Üniversitesi, Fen Edebiyat Fakültesi, Türk Dili ve Edebiyatı Bölümü, (Yozgat, Türkiye), funda.capan.ozdemir@bozok.edu.tr, ORCID ID: 000o-0002-3950-4842 [Makale kayit tarihi: 25.02.2019-kabul tarihi: 17.03.2019; DOI: 10.29000/rumelide.541034] 
principle of acting as a basic broadcasting policy in the interests of Yozgat. Yozgat, Turkey's political, social, carries agenda taking very seriously the cultural and economic issues. In this context, "Bozok" is a newspaper that pushes the boundaries of regional journalism and is sensitive to the problems of the country. In our study, we made a thematic research topic based on Abbas Sayar's journalist experiences and the owner of the newspaper Abbas Sayar between 1953 and 1954 as the most representative example of Yozgat's press history. Our review also answers questions about how, how and why the political, social and cultural problems of Yozgat in the 1950s were discussed in newspaper columns. We tried to clarify the unknown aspects of Abbas Sayar as a journalist known for his works in novels and poetry in Turkish literature.

Key words: Provincial newspaper, republican period, Bozok.

\section{Giriş}

Yozgat yerel basını, birbirinden farklı özelliklere sahip gazeteler ve gazetelerde çıkan haberlerin yanı sıra güncel, sosyal, siyasi, iktisadî ve kültürel konular hakkında kaleme alınan yazılar ve yazarlar bağlamında dikkate değer bir çeşitliliğe sahiptir. Cumhuriyet döneminde, gazetelerin pek rağbette olmadığı ve radyonun da yok denecek kadar az olduğu 1940'lı yılların başından itibaren, sadece bir valinin evinde ve bir de halkevinde radyo bulunmaktadır (Saygı, 2000: 23). Bu yıllarda, biri Yozgat'ın merkezinde yer alan Çapanoğlu Büyük Camii’ye yakın, diğeri de yine Yozgat'ın merkezindeki Cumhuriyet alanında ve halk tarafindan "Saathane" denen "Saat Kulesi" yönüne doğru kurulan iki tane hoparlör sayesinde bütün bir şehre haberler duyurulur. Ayrıca, şehirdeki evlerin çoğunda radyo bulunmadığı gibi elektrik de yoktur (Saygl, 2000: 23). Bir kuruşa satılan ve çok küçük boyuttaki “Ajans Haberleri”, Yozgatlının dünya ile arasındaki ilişkiyi sağlar. Yozgat basın tarihindeki dikkate değer ilk adım 1945 tarihinde Neşet Tanrıdağ, Mustafa Tütüncü ve Kadir Koçak tarafından Sivas'tan satın aldıkları matbaa ile birlikte Yozgat'ta "Çağlayan” gazetesini çıkarmalarıdır. Daha sonra ortaklıktan ayrılan Neşet Tanrıdağ, bu gazeteyi tek başına Ankara'da çıkartarak, Yozgat’a gönderir. "Çağlayan” sanatsal yönü ağırlıklı ve içinde çok ciddi yazılar bulunan bir gazete olmasına rağmen, aynı şehirde çıkan "Hakikat" gazetesi ile birlikte yayın hayatına uzun süreli devam edemez (Saygi, 2000: 23).

Güncel, sosyal, siyasi, iktisadî ve kültürel konular hakkında kaleme alınan yazılar, yazarlar ve haberlerin sunumu bağlamında geniş, zengin bir içeriğe sahip ve Yozgat basın tarihine çok mühim katkılar sağlayan "Yozgat Gazetesi" hakkındaki malumatlar, 1927 tarihine dayanır (Saygl, 2000: 23). Bu tarihte, Özel İdare Müdürlüğü tarafından Vilayet Matbaası’nda çıarılan “Yozgat Vilayet (İl) Gazetesi”, yayın hayatını 1974 yılına kadar sürdürür. Bu arada, 1974 yllında "Hür Yozgat" adıyla Osman Hakan Kiracı tarafindan yayın hayatına sunulur. Daha sonra "Hür Yozgat" gazetesinin ismi, 1980'li yllarda "Yozgat Gazetesi" olarak değiştirilerek yayın hayatına devam eder. "Yozgat Gazetesi”, 1996 tarihine kadar günlük, 19962016 tarihleri arasında haftalık olarak ve on beş günde bir olmak üzere yayımlanır (Saygı, 2000: 23). 2016 tarihinden sonra ve hâlen günümüzde ise, İnternet'te yayımlanan bir gazete olarak her gün çıarılmaya devam etmektedir. Ayrıca, bayram ve benzeri özel günlerde basılı olarak yayımlanır. "Yozgat Gazetesi", bilhassa bayram özel sayılarında Babıali’nin ünlü yazarlarına köşe açan yönüyle de dikkati çeker. Türk medyasının Tayfun Talipoğlu, Prof. Dr. Haluk Şahin, Orhan Erinç, Nazmi Bilgin, Ardan Zentürk, Melih Âşık, Oktay Ekşi, Faik Çetiner gibi belli başlı ünlü yazarları, Yozgat Gazetesi'nin bayram sayılarında köşe yazıları kaleme almışlardır (Kiracı, 1990: 2-7). Orta Anadolu'da Ankara hariç olmak üzere, her dalda basın başarı ödülleri kazanan bir gazetedir. Toplam ödül sayısı yirmi birdir. Genel itibariyle Yozgat'ta dikkate değer ve etkin bir gazetedir. 
Yozgat Gazetesi'nin sahibi olan Osman Hakan Kiracı, 1951 Yozgat doğumludur. Mesleğe lisede duvar gazeteciliği ile başlar. 1969 yılında "Yeni Yozgat" gazetesinde muhabirlik yapar. Askerlik görevinin öncesinde ve sonrasında çeşitli gazete ve ajansların Yozgat muhabirliği görevlerinde bulunur. Yozgat’ta 1971-73 yıllarında "Hizmet" ve "Hürses" gazetelerini yayımlar (Saygl, 2000: 23). 1974 yılından itibaren Yozgat Gazetesi’ni yayın hayatına sokar. 1974 yllında Yozgat Gazeteciler Cemiyeti’ni kurar. Yaklaşık olarak kırk yıldır Yozgat Gazeteciler Cemiyeti Başkanlığı görevini sürdürmektedir. Ayrıca, 1976-1994 yılları arasında on sekiz yıl boyunca Hürriyet gazetesinin Yozgat muhabirliği görevini yapmıştır. "Yozgat Bayram Gazetesi” çalışmasıyla Anadolu'daki basın kuruluşlarına örnek olmuştur (Kiracı, 1990: 2-7). Merkezi Ankara'da bulunan Gazeteciler Cemiyeti tarafindan 1980-1990 tarihleri arasında "Son 10 Yllın En Başarılı Gazetecileri” arasında yer almıştır. Türkiye'nin saygın basın meslek kuruluşları tarafından Yozgat Gazetesi adına çeşitli dallarda bugüne değin yirmi bir basın başarı ödülüne layık görülmüştür. Ayrıca Osman Hakan Kiracı'ya 2018 yllında Ankara Üniversitesi İletişim Fakültesi'nce "Meslekte 50. Yll” ödülü verilir. Kiracı, aynı zamanda yaklaşık dört yıldan beri Türkiye’nin en güçlü yerel medya örgütü olan Türkiye Gazeteciler Konfederasyonu'nda genel koordinatör ve yönetim kurulu üyesi olarak görev yapmaktadır (Kiracı, 1991: 1-9). 1974 yılından itibaren Yozgat Gazetesi'nde makaleler kaleme alan Kiracı, tespit, tasvir, değerlendirme, tenkit, hedef gösterme, tavsiye etme ve öğretme tarzındaki ifade bolluğuyla çeşitli siyasî ve sosyal makaleler kaleme alır. Yozgat'in meseleleri başta olmak üzere sosyalkültürel konularda, öğretim-eğitim, iktisat hakkında kaleme aldığı yazılarda siyasetin açtığı kapıdan girerek bazı görüş ve hükümlere ulaşır. Ele aldığı meselelerin hangi uygulamaların bir sonucu olduğu, nasıl uygulamalar yapılması gerektiği şeklinde ve bilhassa program mahiyetinde mukayeseler ve tavsiyelerde bulunur.

1955-1956 tarihleri arasında çıkan "Vurun Abalıya" haftalık gazetesi, 1957-1975 ylları arasında yayımlanmaya devam ederek 1975 tarihinde satılan "Hakikat" gazetesi, 1977 tarihine kadar yayın hayatına devam eden "Mücadele", "İleri”, "Çeşka", "Yeni Şafak", "Yeşil Çamlık", "Hizmet Haber", "Gürses”, "Şirin Yozgat”, "Yeni Çeşka”, "Sabah”, 1966'dan 1974'e kadar devam eden "Yeni Yozgat", "Boğazlıyan Postası" (1968), 1968-1984 yılları arasında Hilmi Gönenç tarafından çıkarılan "Anadolu Gazetesi”, Nazım Kayhan tarafından çıkarılan "Sabah Gazetesi” (1975), 1979 tarihinden itibaren Rasim Kayhan tarafından çıkarılan "Haber" gazetesi, Şakir ve Hamdullah Akdoğan tarafından çıkarılan "Sürmeli" gazetesi, Bekir Çaylak ve Muammer Karadeli tarafından çıarıllan "Yeni Ufuk" gazetesi, "Yeni Gün” gazetesi, Gazi Bahçeci tarafından çıarılan "Alternatif” haftalık gazetesi, "Yozgat Haber”, "Bozok Kent" ve "Yozgat Gazetesi”, Yozgat basın tarihinin belli başlı gazeteleridir.

\section{Yozgat sevdalısı yazar Abbas Sayar ve "Bozok Gazetesi"}

Yozgat Gazetesi'nin öne çıkan yazarlarından biri de derin tefekkürü, samimî Yozgat sevgisiyle, köklü bir edebiyat zevkinin terbiyesinden geçen Yozgatlı yazar Abbas Sayar'dır. İstanbul Üniversitesi Edebiyat Fakültesi'nde okurken başladığı gazetecilik mesleğinin yanı sıra roman yazarı ve üstün kabiliyetleri olan bir şairdir. İlk romanı "Yılkı Atı" ile TRT ödülünü, "Çelo" romanı ile Türk Dil Kurumu ödülünü, üçüncü romanı ise "Can Şenliğıı" ile Madaralı ödülünü kazanır (Altınkaynak, 2017: 681-682). "Yılkı Atı" adlı romanı Fransızca ve Rusça gibi pek çok dile çevrilir. Daha sonra "Yorganımı Sıkı Sar", "Dik Bayır" ve "Tarlabaşı Salkım Saçak" adlı kitaplarını yayımlar. Çok sayıda şiir yazan Sayar, seçme şiirlerini "Boşluğa Takılan Ses" adlı kitabında toplar. Şair ve yazarlığın dışında boş zamanlarını resim yaparak geçirir (Altınkaynak, 2017: 681-682). Yozgat'ta yaklaşık 40 yıl gazetecilik yapan Sayar, yaşamını Ayvalık'ta sürdürdüğü süre içerisinde, Yozgat Gazetesi’ne gönderdiği yazılarıyla destek verir. Yazarın 50. Sanat yll gibi Ankara'da görkemli bir törenle yapılan kutlamalar ile ilgili pek çok habere rastlamak mümkündür. Öğrencilik yıllarında Bâb-ı Âli’nin terbiyesinden geçen ve gazetecilik mesleğini profesyonel olarak icra 
eden Sayar, Yozgat Gazetesi'ni baskı, mizanpaj, sayfa adedi ve de en önemlisi muhteva bakımından beğenir. Türkiye'de Bayram gazetesi olarak Yozgat'tan böyle bir gazete çıkmasını Yozgat tarihinin önemli bir olayı kabul eder. Bu gazeteyi "Yozgat” şuurunu diriltmesi bakımından, Yozgat'ın içinde ve dışında yürekleri Yozgat özlemiyle yanıp tutuşan bütün Yozgatlıları kendi davalarında kucaklayan bir anlayışla hareket etmesi bakımından takdir eder.

Yozgat basın tarihindeki dikkate değer gazetelerden biri İstanbul Üniversitesi Edebiyat Fakültesi'nde okuyan Yozgatlı yazar Abbas Sayar'ın 1947 tarihindeki öğrencilik yıllarından itibaren İstanbul'da çıkarıp satış için Yozgat'a gönderdiği "Bozlak" gazetesidir. "Bozlak" gazetesi, on beş günde bir yayımlanır ve bilhassa mahalli konuları içerir. Bu gazete, o günleri yaşayanların anlattığına göre Yozgat’ta oldukça etkili olur. Gazetede yer alan siyasî ve eleştirel içerikli yazılar, halk için çok şaşırtıcı olur ve halkın değer yargılarını değiştirerek halk için bir "cesaret kapısı" haline gelir. Yozgat basın tarihinin en yüksek baskı sayısına ulaşan "Bozlak” gazetesi, İstanbul'dan dönen Abbas Sayar tarafından adının değiştirilmesiyle "Bozok" adıyla yayın hayatına devam eder. Daha önce on beş günde bir yayımlanan gazete, günaşırı çlkmaya başlar ve 1950'den 1990'lı yıllara kadar yayımlanmaya devam eder. Bu gazete yazarlarının farklı bir özelliği; temel ödevleri olarak Yozgat'ın göz ardı edilen veya umursanmayan sorunlarını enine boyuna inceleyip, çözümleriyle birlikte kamuoyunun bilgisine sunmalarıdır. Daha çok edebiyat alanındaki eserleriyle tanınan Abbas Sayar, "Yozgat’ta gazetecilik, çileyi başörtüsü yapmaktır." sözüyle hatırlanan ve her türlü maddî ve manevî zorluklara rağmen gazetecilik mesleğine sevdalı bir yazardır. Yozgat sevdası ile gazetecilik aşkını "Bozok" gazetesinde buluşturan kişidir. Sayar, T.C. Başvekalet Basın-Yayın ve Turizm Umum Müdürlüğü’nün E/260 nolu basın kartı sahibidir (Saygı, 2000: 23).

Gazete sayfalarında dikkati çeken özelliklerden biri de Yozgatlılara hitaben yazılan gazetene sahip çı ihtarıdır. "Yozgatlı. Bu gazete senin için çıkıyor. Yaşatmayı vazife bil." ve "Bozok'u Okuyunuz ve Okutunuz.” gibi ihtarlar, Yozgat’a sahip çıma şuuruyla tanınan Abbas Sayar'ın kaleminden çıar (Sayar, 1954: 188-1). Maddî ve manevî çeşitli zorluklarla bu gazeteyi Yozgat'ın menfaatlerini koruyup kollamak amacıyla çıaran Abbas Sayar, bu sahip çıkmak meselesine ayrı bir ehemmiyet verir; çünkü gazeteye sahip çımak demek, Yozgat'a, Yozgat'ın meselelerine sahip çıkmak demektir. 11 Kasım 1953 tarihinde Şefaatlili mahlashı bir şairin kaleminden çıkan "Oku BOZOK'u” başlıklı şiir de bu bağlamda dikkate değerdir:

\author{
Oku BOZOK'u \\ "İnsanlar inceldi, devir inceldi \\ Hareket inceldi, tavir inceldi \\ Müslüman inceldi, ... inceldi \\ Yozgatlı hemşerim durmadan oku \\ Hemi oku hemi okut Bozok'u \\ Senin için çalışanı bilirsin \\ Yatan ile, yarışanı bilirsin \\ Şerefin yücedir şanı bilirsin... (Şefaatlılı, 1953: 2).
}




\section{Sosyal, ekonomik ve siyasî meseleler bağlamında Yozgat}

Bozok Gazetesi'nin belli başlı özelliklerinden birisi, Yozgat'ın sorunlarını gündeme getirmek ve bu yolla halkı ve konuyla ilgili yetkilileri sorunlardan haberdar etmek ve pratik çözüm teklifleri sunmaktır. Gazetenin öne çıkan bu özelliği bir yayın politikası olarak benimsenmiştir. Ayrıca, 1950'li yılların Yozgat'ının sosyal, ekonomik ve siyasî meseleleri gündeme getirilerek gazete okurlarında bir şuur oluşturulmaya çalışılmıştır. Bu bağlamda Abbas Sayar, bir Yozgat sevdalısı olduğu kadar bir münevver kimliğiyle Yozgat'ın sosyal, ekonomik ve siyasî meselelerine duyarlı bir gazete yazarıdır. Dolayısıyla, gazetedeki haberlerin sunumunda meselelere dair geniş̧ bir bakış açısının yanı sıra eleştirel bir yaklaşım söz konusudur.

Bozok Gazetesi'nde yer alan haberlerin yayımlanma amaçlarından biri de Yozgat'in 1950'li tarihlerde ihtiyaç duyduğu meseleleri gündeme getirmek ve sorunlara çözümler üretmektir. Kayseri üzerinden geçen Ankara ve İstanbul yolunu kısaltılması hakkında yayımlanan haberler, bilhassa Yozgat için hem bir gelir kaynă̆ı, hem imar ve inkişafına bir sebep olacağı içindir. Bu yol şehrin içinden geçerse mevcut köhne yolun etrafındaki harabe binaların yerine modern ve fenni tesisatl evler yapılması mecburiyeti doğacaktır. Bu hareket vilayetin diğer mıntıkalarının kalkınmasını sağlayacak ve örnek olacaktır. Bu sayede gerek vatandaş ve gerekse memur rahat bir evde oturma imkânı altında huzura kavuşacaktır.

Yozgat'ta yapılması planlanan yeni sinema binasının inşa çalışmalarının hızlandırılması meselesi de gazete sütunlarında yer alır. Yozgatlı vatandaşların ihtiyaçlarından biri de sinemadır. Bu yolla halka estetik, terbiye, fikir, kültür bakımından mühim bir hizmet sunulması, teşvik edilmektedir. Açılacak olan Yozgat sinemasında gösterilecek filmlerin İç Anadolu'nun ruhuna işlemiş göbek havaları filmlerinden ziyade kültürel ve sanatsal yönlerden, halka katkı sağlayacak filmler olmalarına özen gösterilmesi istenmektedir. 7 Aralık 1953 tarihli gazetede yayımlanan Yozgat Şehir Kulübü Nizamnamesi de Abbas Sayar için önemlidir. Kulüp üyelerinin istifadesi için kütüphane, mütalaa salonu, kumardan sayılmayan salon oyunlarının oynandığı mekân, büfe ve hususi yerler kurulmasına yönelik kararlar ve uygulamalar Bozok Gazetesi'nin sütunlarında yer alır. Balo, müsamere, konferanslar ve bu gibi içtimai toplantılar yapılması gerektiğine dair yazılar mevcuttur. Bu gibi çalışmalarının Bozok Gazetesi’ndeki pek çok sayıda ve sıkça tekrarlanması, Yozgat'ın sosyal ve kültürel hayatının canlandırılmasına yönelik bir anlayışın tezahürüdür.

Yozgat gençliği namına istenen spor sarayı da Yozgat'ın ihtiyaçlarındandır. Spor sarayı, memleket evlatlarının yaşamını sportmen, kültürlü, ahlaklı, terbiyeli ve vatanperver nesline beşik olacaktır. Bozok Spor Kulübü’nün kuruluşu da Yozgat'in içinde ve hariçte muvaffak olmuş Yozgatlı sporcuların yerlerini almasını sağlayan bir yuvayı mümkün kılacaktır (Sayar, 1954: 188-1). Bilhassa gazete sahibi Abbas Sayar'ın gözetiminde çıan haber ve yorumların Yozgat'ın meselelerine karşı gösterilen derin bir hassasiyetin neticesi olarak yorumlamak mümkündür. Sayar'ın birlik, beraberlik içinde daima ileriyi görerek hareket edilmesi gerekliliğine işaret eden söylemleri takdire şayandır. Memleket çapında ve sporun her sahasında bir varlık olduklarını ispat etmek ancak bu yolla mümkün olacaktır. Gençlerde çalışmayı, büyüklere ise gençlere destek vermeyi tavsiye eden bu anlayış, Abbas Sayar’ın kaleminin kemal derecesini ispata kâfidir.

Abbas Sayar’ın “dil durmaz kalem susmaz” misali bir anlayışla ele aldı̆̆ı meselelerden biri, 1950’li yılların Yozgat belediyesine düşen işlerdir. Milli korunma kanununu tanıtmak, ürünler için istikrarlı satış fiyatları temin etmek, keyfi esnaf harekâtına mani olmak, gıda maddelerini toz ve kirden, caddeleri pislikten kurtarmak, hıfzıssıhha davasını ele almak ve halletmek, ekmek davasını benimsemek, yollara 
bakmak ve yolları yaptırmak, şehirdeki su darlı̆̆ını önlemek, içme suyunun temizlenmesi, dilenciliği ortadan kaldırmak, şehri imar etmek ve güzelleştirmek gibi pek çok konuya değinen haberler Sayar'ın kültürel birikimiyle gazete sütunlarında derinlemesine işlenir (Sayar, 1954: 189-1).

\section{Kültür ve sanat sayfaları}

Şairliği ve roman yazarlı̆̆ı dışında boş zamanlarını resim sanatıyla geçiren Abbas Sayar, Yozgat'ta gazetecilik yaptığı kırk yıl boyunca "Bozok" gazetesinin kültür ve sanat sayfalarına ayrı bir özen gösterir. Sayar, kültürel donanımı, edebiyat ve gazetecilik alanındaki bilgi ve tecrübesi sayesinde "Bozok" gazetesini baskı, mizanpaj, sayfa adedi ve de en önemlisi muhteva bakımından üstün bir gazete hâline getirir. Öğrencilik yıllarında Bâb-ı Âli’nin terbiyesinden geçen ve gazetecilik mesleğini profesyonel olarak icra eden Sayar'ın tüm bu deneyimlerini kullanarak "Bozok” gazetesi vasitasıyla Yozgat'a büyük hizmetlerde bulunması, dikkate değerdir. Sayar, Türkiye'de Yozgat'tan "Yozgat Gazetesi” ve "Bozok" gibi gazetelerin çıkmasını Yozgat tarihinin önemli bir olayı olarak kabul eder. Yozgat’ın içinde ve dışında yürekleri Yozgat özlemiyle yanıp tutuşan bütün Yozgatlıları kendi davalarında kucaklayan bir anlayışı benimseyen her iki gazete de Yozgat ve Yozgatlılar için bir dönüm noktasıdır. Gazetede yer alan kültür ve sanat sayfaları da okurlarını bu alanda bilgilendirmesi bakımından mühim bir kazançtır.

"Bozok" gazetesinin kültür ve sanat alanındaki yazılarıyla tanınan Cemalettin Demir Kazık, 11 Aralık 1953 tarihli "Onlar ve Biz" başlıklı yazısında Avrupa medeniyeti ile Türk-İslâm medeniyetini mukayese etmesi dikkate değerdir (Kazık, 1953: 78). Türklerin tarih boyunca Avrupa medeniyetine örnek olması, Türk sanatının kemâl seviyelerine gelişi, Türklerden tarih boyunca icatlar yapan pek çok âlimler yetişmiş olması, kültür ve sanat alanında diğer pek çok dünya milletlerine örnek olması gibi konular üzerinde durur. Harpler sebebiyle bazı tarihlerde bu tür yükseliş hareketleri kesintiye uğrar. Tarihin geneli üzerinde düşünen yazar, Türklerin tarih boyunca sanat ve kültüre önem vererek, milletlerini yükseltmek için azim ve gayretle kendilerine düşen vazifeleri yapmaları sayesinde yükseldiklerini ifade eder. Ancak yaşadığı devirde sanatsal faaliyetlerin yok denecek kadar azaldığını, sanata ve sanatkâra yeterince kıymet verilmediğini eleştirel bir yaklaşımla ifade eder (Kazık, 1953: 78).

Sanat Mektepleri Cemiyeti Yozgat Şubesi Başkanı Necnet Türköz’ün "Sanat Mektepleri Cemiyetleri” başlıklı yazısı, bu cemiyetin Yozgat'taki çalışmalarından Bozok okurunu haberdar eder (Kazık, 1953: 78). Cemiyetin, memleketimizde sanatın ve sanatkârın yükselmesini teşvik etmek, cemiyetin üyeleri arasında yardımlaşmayı temin etmek, meslek tesanüdünü ve kültür seviyesini yükseltmek, işsiz kalan üye sanat mekteplerinden yeni mezun olanlara iş temin etmek, üyelerin yeni buluşlarını ve icatlarını tatbik mevkiine koymak için yardımda bulunmak, mesleklerinde yükselmek isteyen kabiliyetli sanat mektepleri mezunu gençlere yardım etmek, Türkiye'de bu tür alanlardaki öğretimin gelişmesine ve öğretimine çalışmak gibi faaliyetleri, Yozgatlıların 1950'li yıllarda duyduğu ihtiyaçtır.

“Bozok” gazetesinin kültür ve sayfalarında Türkiye genelindeki Hz. Mevlana’yı anma faaliyetleri, Yozgat'ta sanat hayatının canlandırılmasına yönelik faaliyetler, müzik konserlerine, temsillere, sanat günlerine olan rağbetin arttırılmasına yönelik faaliyetler, okullar arası şiir müsabakası gibi çalışmalar ve bu tür konulardaki haberler söz konusudur. Hepsi de Yozgat'ın ihtiyaç duyduğu kültür ve sanat atmosferini canlandırmak ve halkın kültürel seviyesini yükselterek, halka katkı sağlamak içindir. 


\section{Biçim ve içerik}

“Bozok" gazetesinin sütunlarında, genel olarak memleketimizin 1950'li yllara dair sosyal, ekonomik, siyasî ve kültürel meselelerine dair çeşitli haberler ve ilanlar yer almaktadır. Başta Abbas Sayar olmak üzere çoğunlukla Yozgatlı yazarların şehirlerine dair kaleme aldıkları köşe yazıları, Yozgat'ın bu tarihlerdeki sorunlarını aydınlatmaktadır. Kültür ve sanat sayfalarında yer alan Yozgatlı şairler ve yazarlara ait şiirler ve hikâyeler, karikatürler, gazetenin bayram özel sayılarında çıan yazılar, dinî içerikli yazılar, Türk-İslam tarihine dair aydınlatıcı bilgiler, insan sağlığına dair malumatlar, hayata ve insan ilişkilerine dair özlü sözler, okurların bilgi ve kültür seviyelerini yükseltir ve okurlara eleştirel bir bakış açısı kazandırır.

İstanbul Üniversitesi'nde öğrencilik yıllarından itibaren Babıali’nin terbiyesinden geçerek gazetecilik alanındaki bilgi ve tecrübelerini arttıran Abbas Sayar'ın sahibi olduğu ve yazı işleri müdürlüğü görevini üstlendiği "Bozok" gazetesi, baskı, mizanpaj, sayfa adedi ve muhteva bakımından dönemine göre oldukça üstün özelliklere sahiptir. Biçim ve içerik yönünden 1953-1954 tarihlerinde incelediğimiz tüm nüshalarında Abbas Sayar'ın sanatkâr hassasiyetini tespit etmek mümkündür. Yozgat'ın meselelerini dikkate değer bir sunuş tarzıyla gündeme getiren Sayar, 1950'li yılların Yozgat'ını tüm yönleriyle aydınlatmaya çalışır. Gazetenin dikkat çekici, kırmızı renkli ve yazı tipi boyutu oldukça büyük olan başlı̆̆l, okurların ilgisini çeken manşetleri, haberlerin içerik yönünden tasnifine özen gösterilmesi, yazıların anlaşılır ve okunaklı oluşu, nüshalarda kenar boşluklarının yer alması, yazım kurallarına ve noktalama işaretlerinin kullanımına riayet edilmesi, bu gazetenin en belirgin özelliklerindendir.

\section{Sonuc}

"Bozok" gazetesi, bir taşra gazetesi olarak Yozgat'ın sorunlarını ve haberlerini yakından takip etmesi ve bunlarla ilgili başta devlet büyükleri olmak üzere Yozgatlıları bilgilendirmesi bakımından çok etkin ve dikkate değer bir gazetedir. Halkın dertlerini kendi derdi, sevinçlerini ise kendi sevinci olarak gören bir yayın politikası benimsemesi sebebiyle halk tarafından oldukça rağbet görür. Başta Abbas Sayar olmak üzere "Bozok" gazetesi yazarlarının Yozgat'ın menfaatlerini üstün tutan söylemlerinden anlaşıldı̆̆ı üzere Yozgat'ın ihtiyaç duyduğu alanlarda Yozgat'a hizmet etmek, gazetenin genel bir yayın politikası hâline gelmiştir. Yazarların tespit, tasvir, değerlendirme, tenkit, hedef gösterme, tavsiye etme ve öğretme tarzındaki ifade bolluğuyla çeşitli siyasî ve sosyal makaleler kaleme alınır. Yozgat'ın sosyal-kültürel konularında, öğretim-eğitim ve iktisat gibi meseleler hakkında kaleme alınan yazılarda siyasetin açtığı kapıdan girilerek bazı görüş ve hükümlere ulaşılır. Ele aldığı meselelerin hangi uygulamaların bir neticesi olduğu, nasıl uygulamalar yapılması gerektiği şeklindeki yazıların yanı sıra bilhassa program mahiyetinde mukayeseler ve tavsiyelerde bulunulur. Bu bağlamda, yazarların siyasî meseleleri ele alırken, kendilerine has olan üslûbu, kompozisyon itinası, dengeli tavrı, ölçme tartma kabiliyeti asla kaybolmaz. Memleketin siyasî, sosyal ve kültürel meselelerini geniş bir bakış açısıyla ele alan yazarlardan öğrenilen bilgiler ve haberler, Yozgat'ın meselelerini gündemde tutması bağlamında mühimdir. "Bozok" gazetesinin incelediğimiz tüm nüshalarında Abbas Sayar'ın sanatkâr hassasiyetini tespit etmek mümkündür. Gazetenin yazı tipi boyutu, başlığı, okurların ilgisini çeken manşetleri, haberlerin içerik yönünden tasnifindeki itina, yazıların anlaşılır ve okunaklı oluşu, yazım kurallarına ve noktalama işaretlerinin kullanımına riayet edilmesi, gazete sütunlarındaki düzen, bu gazetenin en belirgin özelliklerindendir. Tüm bu hususiyetleriyle Yozgat sevdasını ve gazetecilik aşkını "Bozok" gazetesinde buluşturan Abbas Sayar, bu bağlamda Türk edebiyatı yazarları içinde fikrî ve hissî planda temsilî bir şahıstır. Sayar’ın zengin kültür ve bilgi hazinesiyle yayımladığı "Bozok" gazetesi, memleket 
meselelerini geniş bir bakış açısıyla idrak etmek ve eleştirel yaklaşımlar geliştirmek bağlamında okurlar için bir kazançtır.

\section{Kaynakça}

Altınkaynak, Hikmet. (2017). Abbas Sayar Maddesi, Türk Edebiyatında Yazarlar ve Şairler Sözlüğü, İstanbul: Can Yayınları.

Kazık, Cemalettin Demir. (1953). Onlar ve Biz, Bozok Gazetesi, Yıl: 6, Sayı: 78, Yozgat: A. Sayar Matbaası.

Kiracı, Osman Hakan (1990). Yozgat 17 Yaşında, Yozgat Gazetesi, Yıl: 18, Sayı: 3883, Yozgat: Yozgat Matbaası.

Kiracı, Osman Hakan (1991). Gündem, Yirminci Ylln Anlamı, Yozgat Gazetesi, Yll:18, Sayl: 4130, Yozgat: Yozgat Matbaası.

Saygı, Mehmet. (2000). 1950-20oo Arası Yozgat Basını, Bütün Yozgat Dergisi Mart Sayısı, Yozgat.

Sayar, Abbas. (1954). Dört Dava, Bozok Gazetesi, Yıl: 7, Sayı: 188, Yozgat: A. Sayar Matbaası,1.

Sayar, Abbas. (1954). Dört Dava, Bozok Gazetesi, Yıl: 7, Sayı: 189, Yozgat: A. Sayar Matbaası,1.

Sayar, Abbas. (1991). Sizin haritanızda "Yozgat" diye bir şehir var mı?, Yozgat Gazetesi, Yozgat: Yozgat Matbaası,1.

Sayar, Abbas. (1991). Kutlama mesajı, Yozgat Gazetesi, Yozgat: Yozgat Matbaası 1-3.

Sayar, Abbas. (1991). Hemşehrilerime tekmil ve teşekkürlerimle, Yozgat Gazetesi, Yozgat: Yozgat Matbaası 1-3.

Sayar, Abbas. (1991). Her gün kurbanım sana, Yozgat Gazetesi, Yozgat: Yozgat Matbaası 1-9.

Sayar, Abbas. (1991). On bir ayın sonrasını Yozgat’', Yozgat Gazetesi, Yozgat: Yozgat Matbaası yll: 17, Sayl: 3966, 2.

Sayar, Abbas. (1991). Sayın Lütfullah Kayalar'a, Yozgat Gazetesi, Yozgat: Yozgat Matbaası s. 1-9.

Sayar, Abbas. (1993). Bir doğa yadigarı, Yozgat Gazetesi, Yozgat: Yozgat Matbaası 20,1, 4896,

Sayar, Abbas. (1993). Ehval-i Yozgat, Yozgat Gazetesi, Yozgat: Yozgat Matbaası Yll: 20, 4893, 01.06.1993, 1-3.

Sayar, Abbas. (1993). Sürgünden sürgüne, Yozgat Gazetesi, Yozgat: Yozgat Matbaası 1.3.1974, $19,1$.

Sayar, Abbas. (1993). Yozgat basınına göz atıs,, Yozgat Gazetesi, Yozgat: Yozgat Matbaası 20, 1.

Şefaatlili (1953). “Oku Bozok’u” Şiiri, Bozok Gazetesi, Yıl: 6, Sayı: 64, Yozgat: A. Sayar Matbaası.

Türköz, Necdet. (1953). Sanat Mektepleri Cemiyetleri, Bozok Gazetesi, Yıl: 6, Sayı: 78.

Uğurcan, Sema (2012). Edebiyatımız I Edebiyat Tarih İlişkisi, İstanbul: Dergâh yayınları. 